\title{
Cosmic ray modulation associated to small and moderate geomagnetic storms during minimum solar activity
}

Carlos Roberto Braga' ${ }^{1}$, Alisson Dal Lago, Walter Demetrio Gonzalez Alarcon

National Institute for Space Research- INPE - Brazil

E-mail: crbraga@dge.inpe.br; dallago@dge.inpe.br; gonzalez@dge.inpe.br

\section{Nelson Jorge Schuch}

Southern Regional Space Research Center-CRS/INPE - MCT - Brazil

E-mail: njschuchelacesm.ufsm.br

\section{Marlos Rockenbach da Silva}

Universidade do Vale do Paraiba - UNIVAP - Brazil

E-mail: marlosrs@gmail.com

\section{Takao Kuwabara, John W. Bieber, Paul Arthur Evenson}

Bartol Research Insitute and Departament of Physics and Astronomy, University of Delaware - USA

E-mail: takaodbartol.udel.edu; jwbieber@bartol.udel.edu;

evensoneudel.edu

\section{Kazuoki Munakata, Chihiro Kato}

Faculty of Science, Shinshu University - Japan

E-mail: kmuna00@shinshu-u.ac.jp; ckatodshinshu-u.ac.jp

\section{Munetoshi Tokumaru}

Solar-Terrestrial Environment Laboratory, Nagoya University - Japan E-mail: tokumaruestelab.nagoya-u.ac.jp

\section{Marcus Leslie Duldig}

Australian Antarctic Division - Australia

E-mail: marc.duldiglaad.gov.au

\section{John Humble}

School of Mathematics and Physics, University of Tasmania - Australia E-mail: john.humbledutas.edu.au

\section{Ismail S. Sabbah}

Astronomy Department, Faculty of Science, King Abdulaziz University Saudi Arabia

E-mail: sabbahsomeyahoo.com

\section{Hala K. Al Jassar; Madan M. Sharma}

Physics Department, Faculty of Science, Kuwait University - Kuwait E-mail: hala@kuc01.kuniv.edu.kw; sharma@kuc01.kuniv.edu.kw

\section{${ }^{1}$ Speaker}




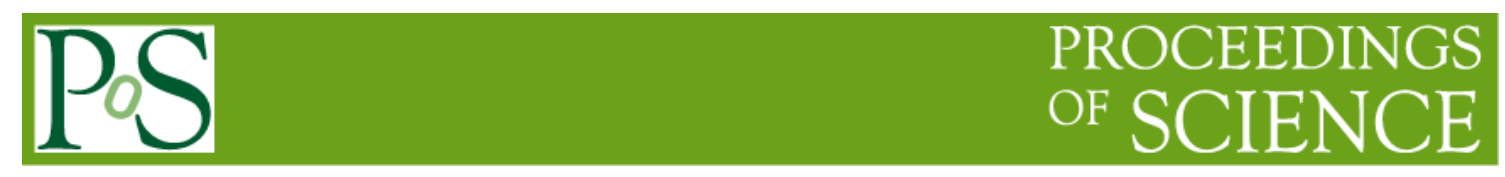

\begin{abstract}
Inhomogeneities in the interplanetary magnetic field produced by interplanetary disturbances associated with coronal mass ejections are transmitted fast to remote locations as a directional anisotropy of high-energy cosmic ray intensity due to the high speed and long parallel mean free path of energetic particles. Cosmic ray intensity increases or decreases before the Forbush decreases have been observed with a single directional channel especially for strong geomagnetic storms associated with strong interplanetary shocks. The aim of this work is to study cosmic ray precursory phenomena of small and moderate geomagnetic storms from June 26th 2008 to December 31st 2008 (from Bartels rotation number 2387 to 2393), most of them not associated with shocks, by analyzing data from the Global Muon Detector Network consisting of four multidirectional muon detectors. By analyzing muon count rates in 60 directional channels, the pitch angle distribution in a 48-hour period before the storm sudden commencement was studied by two different methodologies: one using the hourly count rate (MPA) and the other using the time derivative of the count rate (VPA). Possible precursors are clear in 4 of the 7 events registered in the selected period, generally observed by the MPA.
\end{abstract}

4th School on Cosmic Rays and Astrophysics

August 25-September 04, 2010

São Paulo, Brazil 


\section{Introduction}

Geomagnetic storms are key effects of space weather near the Earth. Large geomagnetic storms are primarily caused by interplanetary disturbances associated with coronal mass ejections [1]. The passage of a solar wind disturbance at the Earth may produce significant variation in the intensity of galactic cosmic rays (GCRs) with energies up to $\sim 100 \mathrm{GeV}$. By the interaction of $>1 \mathrm{GeV}$ primary galactic cosmic rays with Earth's atmosphere, secondary cosmic rays are created and can be observed by ground-based detectors, such as muons detectors and neutron monitors [2]. Due to the high speed and parallel mean free path of cosmic rays, inhomogenities in the interplanetary magnetic field (IMF), are transmitted fast to remote locations and detected as the enhanced anisotropy of the directional intensity of cosmic rays[3].

Cosmic ray intensity increases or decreases appearing before the Forbush decreases have been observed for a long time [4]. Nagashima et al. [5] suggested the existence of local time dependent precursory decrease of cosmic ray (muon) intensity in front of a shock during the morning (6-12h) and post-shock increase during the evening (18-24h). It was concluded that the precursory decrease is produced by the IMF-collimated outward flow of the low-density cosmic rays from the region behind the shock. Munakata et al. [6] examined cosmic ray precursors of 39 geomagnetic storms with the peak Kp>=7- occurred in the period from 1992 to 1998. In that work, analysis of the pitch angle distribution of high-energy cosmic ray intensity measured by the Nagoya and Hobart muon detectors was done. Selecting 22 storms, each with a good coverage of the sunward IMF direction, they found 15 storms (68.2\%) associated with precursors. Furthermore, a similar analysis using a network of neutron monitor was performed [7] for severe geomagnetic storms in the period from 1978 to 1982. Some precursors were of the "loss cone" type, in which the decrease is confined in small pitch angles around the sunward IMF direction. Other are pre-increases of cosmic ray intensity with pitch angles up to 90 degrees, approaching the shock from the upstream region and reflecting from it [8].

All these studies are related to strong geomagnetic storms associated with strong interplanetary shocks. As far as we know, there is no systematic study for moderate and small geomagnetic storms in terms of their relation to muon observations so far.

In this paper, we analyze the spatial and temporal variations of high-energy GCR intensity using data from the Global Muon Detector Network (GMDN) formed by 4 detectors, which started its operation with full observation coverage in March 2006. The GMDN has a response to the secondary muons related to the primary GCRs with median energies ranging from 50 to $150 \mathrm{GeV}$. These high-energy GCRs have large Larmor radii in the IMF $(\sim 0.2 \mathrm{AU}$ in $5 \mathrm{nT})$ and are less sensitive to small-scale magnetic irregularities in the solar wind.

\section{The Global Muon Detector Network}

The detectors at Nagoya (Japan), Hobart (Australia) and São Martinho da Serra (Brazil) have detection areas of $36 \mathrm{~m}^{2}, 9 \mathrm{~m}^{2}$ and $28 \mathrm{~m}^{2}$, respectively. Each of these detectors is multidirectional, allowing simultaneous measurements of the intensities in various directions of viewing. In December 2010 the detector at Hobart has been engarged to $16 \mathrm{~m}^{2}$. These detectors have an identical design, except for their detection area, consisting of two horizontal layers of 
plastic scintillators, vertically separated by $1.73 \mathrm{~m}$, with an intermediate $5 \mathrm{~cm}$ layer of lead to absorb the soft component radiation in the air. Each layer comprises an array of $1 \mathrm{~m}^{2}$ unit detectors, each with a $0.1 \mathrm{~m}$ thick plastic scintillator viewed by a photomultiplier tube of 12.7 $\mathrm{cm}$ diameter. By counting pulses of the twofold coincidences between a pair of detectors on the upper and lower layers, we can record the rate of muons from the corresponding incident direction. The multidirectional muon detector comprises various combinations between the upper and lower detectors.

One of four detectors is located at Kuwait University (Kuwait), with a detection area of 9 $\mathrm{m}^{2}$. The Kuwait University muon detector is a hodoscope designed specifically for measuring the "loss cone" anisotropy [6,9]. For analyzing Kuwait University data together with the data from the other three detectors of different geometry, we rearrange 529 directional channels in the detector into 13 channels, which are equivalent to those in Hobart having the same detection area $\left(9 \mathrm{~m}^{2}\right)[10]$.

Table 1 summarizes characteristics of the GMDN (adapted from [10]). The median rigidity $\left(\mathrm{P}_{\mathrm{m}}\right)$ of primary cosmic rays observed, calculated by using the response function of the atmospheric muons to the primary particles [11], ranges from 55 to $114 \mathrm{GV}$. The statistical error of hourly count rates ranges from $0.06 \%$ to $0.49 \%$. Each symbol in Figure 1 (from [10]) shows the asymptotic viewing direction, after correction for geomagnetic bending, at rigidity $\mathrm{P}_{\mathrm{m}}$ of each directional channel, as determined using a particle trajectory code [12]. The track through each symbol represents the spread of viewing directions for particles with rigidity in the central $80 \%$ of each directional channel's energy response.

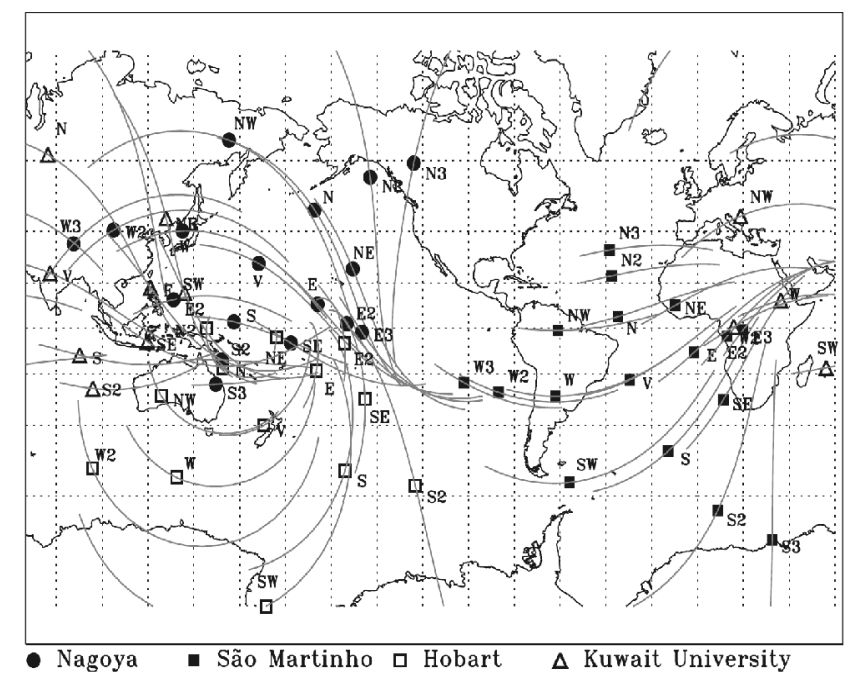

Figure 1: asymptotic viewing directions of the GMDN. Each symbol (filled circles for Nagoya, filled squares for São Martinho da Serra, open squares for Hobart, open triangles for Kuwait University) shows the asymptotic viewing direction (after correction for geomagnetic bending) of each directional channel. The track through each symbol represents the spread of viewing directions corresponding to the central $80 \%$ of each channel's energy response [10]. 
Table 1: Main characteristics of the GMDN (partially adapted from [10])

\begin{tabular}{|c|c|c|c|c|c|c|c|}
\hline \multirow{2}{*}{ Directional channel } & \multirow{2}{*}{$\begin{array}{c}\text { Average } \\
\text { count } \\
\text { rate } \\
10^{4}[\mathrm{cph}]\end{array}$} & \multirow{2}{*}{$\begin{array}{l}\text { Error } \\
{[\%]}\end{array}$} & \multirow{2}{*}{$\begin{array}{c}P_{m} \\
{[G V]}\end{array}$} & \multicolumn{2}{|c|}{$\begin{array}{l}\text { Asymptotic viewing } \\
\text { direction }\end{array}$} & \multirow[t]{2}{*}{$\begin{array}{l}\text { Correlatio } \\
\mathrm{n}\end{array}$} & \multirow[t]{2}{*}{ Regression } \\
\hline & & & & $\begin{array}{c}\text { Latitude } \\
{\left[{ }^{\circ}\right] \mathrm{N}} \\
\end{array}$ & $\begin{array}{c}\text { Longitude } \\
{\left[{ }^{\circ}\right] \mathrm{E}}\end{array}$ & & \\
\hline \multicolumn{8}{|c|}{ Nagoya $\left(35.1^{\circ} \mathrm{N} ; 137.0^{\circ} \mathrm{E}\right)$} \\
\hline $\mathrm{V}$ & 276 & 0.06 & 59.43 & 28.02 & 168.35 & -0.95 & -5.9 \\
\hline $\mathrm{N}$ & 125 & 0.09 & 64.59 & 46.99 & 192.73 & -0.95 & -6.2 \\
\hline $\mathrm{S}$ & 123 & 0.1 & 62.59 & 2.92 & 157.50 & -0.96 & -6.1 \\
\hline $\mathrm{E}$ & 120 & 0.09 & 66.67 & 10.78 & 194.02 & -0.95 & -6.2 \\
\hline W & 126 & 0.09 & 61.76 & 40.15 & 135.00 & -0.96 & -6.2 \\
\hline $\mathrm{NE}$ & 58 & 0.14 & 72.03 & 25.85 & 209.41 & -0.96 & -6.3 \\
\hline NW & 62 & 0.13 & 66.63 & 64.34 & 155.36 & -0.96 & -6.3 \\
\hline SE & 58 & 0.14 & 69.30 & -6.64 & 182.43 & -0.96 & -6.5 \\
\hline SW & 60 & 0.13 & 65.60 & 12.84 & 131.09 & -0.96 & -6.4 \\
\hline $\mathrm{N} 2$ & 61 & 0.13 & 83.02 & 56.12 & 217.00 & -0.97 & -6.7 \\
\hline $\mathrm{S} 2$ & 60 & 0.13 & 80.47 & -14.13 & 152.19 & -0.97 & -6.5 \\
\hline E2 & 58 & 0.14 & 88.32 & 2.03 & 206.75 & -0.97 & -6.5 \\
\hline W2 & 62 & 0.13 & 79.32 & 40.44 & 104.98 & -0.97 & -6.6 \\
\hline N3 & 18 & 0.27 & 105.00 & 59.49 & 236.07 & -0.96 & -6.5 \\
\hline $\mathrm{S} 3$ & 18 & 0.27 & 103.69 & -24.42 & 149.57 & -0.96 & -6.3 \\
\hline E3 & 17 & 0.28 & 113.68 & -1.73 & 213.42 & -0.95 & -6.4 \\
\hline W3 & 18 & 0.27 & 102.97 & 35.57 & 87.46 & -0.96 & -6.4 \\
\hline \multicolumn{8}{|c|}{ Hobart $\left(42.9^{\circ} \mathrm{S} ; 147.4^{\circ} \mathrm{E}\right)$} \\
\hline $\mathrm{V}$ & 83 & 0.12 & 54.58 & -40.02 & 170.48 & -0.83 & -4.8 \\
\hline $\mathrm{N}$ & 29 & 0.20 & 59.00 & -17.50 & 152.52 & -0.82 & -4.5 \\
\hline $\mathrm{S}$ & 30 & 0.20 & 59.00 & -53.91 & 205.96 & -0.84 & -5.0 \\
\hline $\mathrm{E}$ & 30 & 0.20 & 59.00 & -18.57 & 193.53 & -0.81 & -4.4 \\
\hline $\mathrm{W}$ & 29 & 0.20 & 59.00 & -55.58 & 132.35 & -0.84 & -4.8 \\
\hline $\mathrm{NE}$ & 12 & 0.33 & 63.66 & -3.86 & 176.04 & -0.77 & -4.0 \\
\hline NW & 11 & 0.33 & 63.66 & -29.07 & 125.77 & -0.80 & -4.0 \\
\hline SE & 12 & 0.33 & 63.66 & -30.16 & 214.75 & -0.78 & -4.2 \\
\hline SW & 12 & 0.33 & 63.66 & -77.18 & 171.56 & -0.82 & -4.7 \\
\hline N2 & 7.0 & 0.42 & 76.26 & 0.18 & 145.58 & -0.73 & -3.8 \\
\hline $\mathrm{S} 2$ & 7.3 & 0.42 & 76.26 & -57.56 & 236.73 & -0.80 & -4.7 \\
\hline E2 & 7.2 & 0.42 & 76.26 & -6.42 & 205.76 & -0.72 & -3.6 \\
\hline $\mathrm{W} 2$ & 7.1 & 0.42 & 76.26 & -53.21 & 95.60 & -0.81 & -5.0 \\
\hline \multicolumn{8}{|c|}{ São Martinho da Serra $\left(29.4^{\circ} \mathrm{S} ; 306.2^{\circ} \mathrm{E}\right)$} \\
\hline $\mathrm{V}$ & 231 & 0.07 & 55.57 & -22.62 & 330.42 & -0.70 & -4.1 \\
\hline $\mathrm{N}$ & 88 & 0.11 & 59.81 & 5.29 & 325.29 & -0.67 & -3.9 \\
\hline $\mathrm{S}$ & 91 & 0.11 & 59.09 & -48.29 & 347.17 & -0.74 & -4.2 \\
\hline $\mathrm{E}$ & 102 & 0.10 & 61.70 & -10.73 & 358.51 & -0.73 & -4.1 \\
\hline $\mathrm{W}$ & 102 & 0.10 & 58.3 & -29.13 & 298.00 & -0.69 & -4.0 \\
\hline NE & 42 & 0.15 & 66.55 & 10.34 & 350.29 & -0.70 & -3.8 \\
\hline NW & 42 & 0.15 & 62.68 & -0.90 & 299.03 & -0.64 & -3.6 \\
\hline SE & 43 & 0.15 & 65.18 & -30.59 & 11.22 & -0.70 & -3.9 \\
\hline SW & 43 & 0.15 & 62.34 & -56.84 & 304.03 & -0.72 & -4.1 \\
\hline $\mathrm{N} 2$ & 29 & 0.17 & 78.97 & 23.01 & 322.47 & -0.68 & -3.7 \\
\hline $\mathrm{S} 2$ & 30 & 0.17 & 77.29 & -63.13 & 8.76 & -0.68 & -4.0 \\
\hline E2 & 37 & 0.15 & 80.55 & -3.57 & 12.85 & -0.67 & -3.7 \\
\hline W2 & 37 & 0.15 & 74.97 & -27.66 & 273.04 & -0.68 & -3.8 \\
\hline N3 & 3.4 & 0.46 & 98.97 & 33.26 & 321.53 & -0.49 & -4.3 \\
\hline $\mathrm{S} 3$ & 3.5 & 0.46 & 96.87 & -68.56 & 32.6 & -0.62 & -5.8 \\
\hline E3 & 7.5 & 0.30 & 105.01 & -0.056 & 19.97 & -0.67 & -4.8 \\
\hline W3 & 7.7 & 0.30 & 98.77 & -23.70 & 257.92 & -0.59 & -4.4 \\
\hline \multicolumn{8}{|c|}{ Kuwait $\left(29.4^{\circ} \mathrm{N} ; 48.0^{\circ} \mathrm{E}\right)$} \\
\hline $\mathrm{V}$ & 86 & 0.19 & 62.33 & 24.24 & 77.20 & -0.92 & -6.4 \\
\hline $\mathrm{N}$ & 22 & 0.19 & 67.75 & 61.41 & 76.31 & -0.93 & -6.6 \\
\hline $\mathrm{S}$ & 22 & 0.19 & 69.42 & -11.89 & 90.09 & -0.93 & -6.9 \\
\hline $\mathrm{E}$ & 22 & 0.20 & 73.45 & 18.08 & 121.09 & -0.93 & -6.2 \\
\hline
\end{tabular}




\begin{tabular}{|c|c|c|c|c|c|c|c|}
\hline Directional channel & $\begin{array}{c}\text { Average } \\
\text { count } \\
\text { rate }\end{array}$ & Error & $\mathrm{P}_{\mathrm{m}}$ & $\begin{array}{r}\text { Asympt } \\
\text { di }\end{array}$ & $\begin{array}{l}\text { iewing } \\
n\end{array}$ & $\begin{array}{c}\text { Correlatio } \\
n\end{array}$ & Regression \\
\hline $\mathrm{W}$ & 22 & 0.19 & 65.95 & 12.58 & 36.36 & -0.93 & -6.8 \\
\hline $\mathrm{NE}$ & 6.4 & 0.35 & 78.21 & 44.37 & 127.90 & -0.92 & -6.4 \\
\hline NW & 6.5 & 0.34 & 72.86 & 45.12 & 18.76 & -0.93 & -6.6 \\
\hline $\mathrm{SE}$ & 6.5 & 0.35 & 82.32 & -5.99 & 119.67 & -0.92 & -6.3 \\
\hline SW & 6.8 & 0.34 & 73.38 & -17.43 & 56.14 & -0.93 & -7.3 \\
\hline $\mathrm{N} 2$ & 2.8 & 0.47 & 97.93 & 81.94 & 58.93 & -0.90 & -6.4 \\
\hline $\mathrm{S} 2$ & 2.8 & 0.47 & 102.18 & -26.10 & 95.85 & -0.89 & -6.1 \\
\hline E2 & 2.6 & 0.49 & 109.77 & 15.90 & 135.89 & -0.89 & -6.4 \\
\hline W2 & 2.8 & 0.47 & 96.97 & 0.79 & 15.75 & -0.90 & -6.8 \\
\hline
\end{tabular}

\section{Objective and Methodologies}

The aim of this paper is to study cosmic ray precursors of small and moderate geomagnetic storms in a period of minimum solar activity from June $26^{\text {th }} 2008$ to December $31^{\text {st }}$ 2008 (from Bartels rotation number 2387 to 2393). The criteria for selecting events was the presence at least one SSC. We did not adopt any criteria of minimum Kp index, as done in previous studies $[1,5,6]$.

The data used are hourly count rates for all the 60 directional channels of all the four stations of the GMDN. All data were corrected for both the atmospheric pressure and temperature effects. The pressure correction is described elsewhere [13]. The temperature correction is described in section 3.1.

Two different methodologies are used for visualizing possible precursors, as described in section 3.2. Both methodologies show global distribution of cosmic ray intensity in the pitch angle versus time pseudo-color map.

\subsection{Temperature correction}

The negative temperature effect on the muon intensity measured with the surface-level detectors predominantly arises from the increase of muon decays due to the atmospheric expansion. By the expansion, the path length between the muon production point in the high altitude atmosphere and the detector on the ground increases, and more muons decay, leading to decreasing of the detected muon intensity [14]. A significant negative correlation, therefore, is expected between the altitude of the equi-pressure surface and the muon intensity, i.e., the muon intensity decreases with increasing the altitude due to the expansion.

There is a more complex temperature correction methodology [15] but the temperature variation for each atmospheric depth is required. As it is seldom to have such data for all muon detectors we decided to use the simplest methodology [14] in a similar way done by Okazaki and co-authors for the GMDN data of 2006 [10]. Measurements of $100 \mathrm{hPa}$ equi-pressure are made continuously by radio-sonde by the Natural Environment Research Council (NERC) once every 12 hours (close to midday and midnight) in several sites in the world, generally close to airports. For the Nagoya muon detector, we used data of three stations and made a mean of them: Shionomisaki, Tateno and Wajina. For the remaining muon detectors we used data from only one high-altitude measurement site for each detector. Details of the high-altitude measurement site for each muon station is shown in Table 2. 
Table 2: High-altitute measurements sites associated to each muon station.

\begin{tabular}{|c|c|c|c|c|}
\hline \multicolumn{3}{|c|}{ High-altitute measurements sites } & \multirow[b]{2}{*}{ Muon station } & \multirow[b]{2}{*}{$\begin{array}{c}\text { Aproximate } \\
\text { distance }(\mathrm{km})\end{array}$} \\
\hline Name & $\begin{array}{c}\text { Geographic } \\
\text { latitude } \\
\text { (degrees) }\end{array}$ & $\begin{array}{c}\text { Geographic } \\
\text { longitude } \\
\text { (degrees) }\end{array}$ & & \\
\hline Shionomisaki & $33.5 \mathrm{~N}$ & $140.1 \mathrm{E}$ & Nagoya & 200 \\
\hline Tateno & $36.0 \mathrm{~N}$ & $140.1 \mathrm{E}$ & Nagoya & 400 \\
\hline Wajina & $37.4 \mathrm{~N}$ & $136.9 \mathrm{E}$ & Nagoya & 300 \\
\hline Porto Alegre & $30.0 \mathrm{~S}$ & $308.8 \mathrm{E}$ & São Martinho da Serra & 260 \\
\hline Kuwait & $29.2 \mathrm{~N}$ & $48.0 \mathrm{E}$ & Kuwait & 10 \\
\hline Hobart & $42.8 \mathrm{~N}$ & $147.5 \mathrm{E}$ & Hobart & 30 \\
\hline
\end{tabular}

The altitude of $100 \mathrm{hPa}$ equi-pressure surface (henceforth called the "the altitude of 100 $\mathrm{hPa}$ ") is shown in the botton panel of Figure 2. The observed deviation at Nagoya (red curve in upper panel of Figure 2) shows a seasonal variation with a maximum in the winter period in the northern hemisphere and a minimum in the summer. The deviation is calculated subtracting and dividing the result by the yearly mean of the count rate. The anti-correlation between the observed muon deviation and the altitude of $100 \mathrm{hPa}$ is evident and the temperature corrected deviation (black curve) seems to have the seasonal variation eliminated.

For the vertical directional channel of Nagoya, the correlation coefficient is -0.95 and the regression coefficient is $-5.9 \% / \mathrm{km}$. Previous results using muon data from 2006 and temperature data only from Shionomizaki are -0.95 for the correlation coeficient and $-6.83 \% / \mathrm{km}$ for the regression coefficient [10]. For all the 60 directional channels in the GMDN, we calculated the correlation and regression coefficients using pressure corrected data in the same way as for the vertical directional channel of Nagoya. All the coefficients calculated in the present paper are listed in the last two columns of Table 2 . 


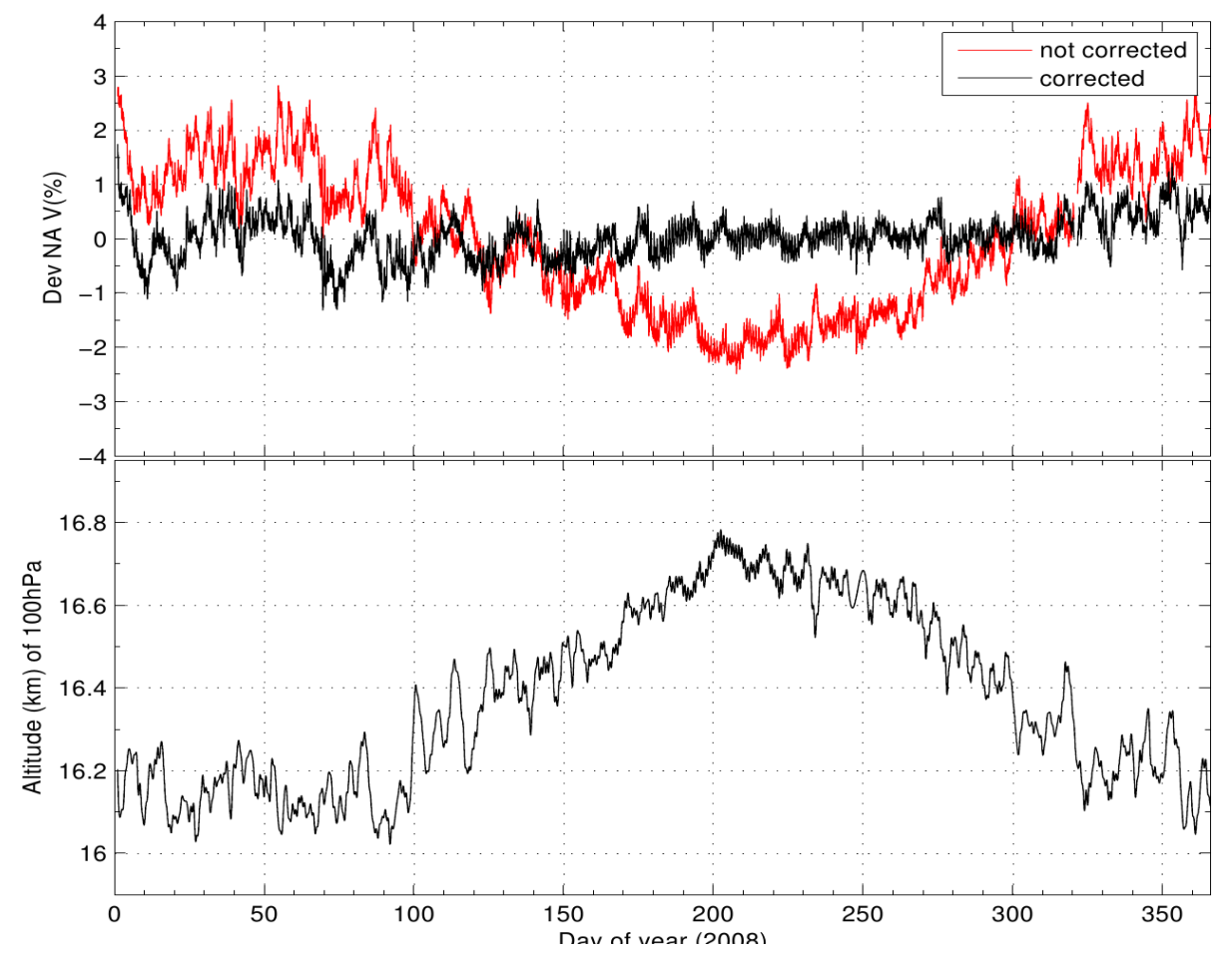

Figure 2: temperature correction for the vertical directional channel of Nagoya. Upper panel: the muon rate $(\%)$ in the vertical direction of Nagoya corrected (black curve) and uncorrected (red curve) for the temperature effect. Lower panel: the altitude of the the 100hPa equi-pressure surface in $\mathrm{km}$.

Similarly than done by Nagoya, a temperature correction of the vertical directional channel of Kuwait seems to eliminate the seasonal variation. Both Nagoya and Kuwait are stations located in the north hemisphere where the summer is in the middle of the year, in the same period than the altitude of $100 \mathrm{hPa}$ is maximum. The maximum difference between the corrected and not corrected deviations is about $2 \%$ for Nagoya and Kuwait.

The muon detectors of São Martinho da Serra and Hobart are located in the south hemisphere and have the yearly variation in opposite phase: the altitude of $100 \mathrm{hPa}$ has the lowest values in the middle of the year during the winter in the south hemisphere. The maximum difference between the corrected and not corrected deviations is about $2 \%$ for Hobart and $1 \%$ for São Martinho da Serra. An explanation for the lower differences for data of São Martinho da Serra can be the amplitude of the annual variation of the altitude of $100 \mathrm{hPa}$ : while for Nagoya, Kuwait and Hobart it is more than 600 meters, for São Martinho da Serra it is less than 400 meters.

In summary, the twice-a-day $100 \mathrm{hPa}$ altitude measurements seem to correct properly temperature effect in a yearly perspective. Temperature effect correction in a hourly perspective are still an open question.

\subsection{Pitch angle analysis}

We use hourly muon count rates in all directional channels in the GMDN after correcting for the atmospheric pressure effect. The hourly count rates were subtracted and divided by the 
mean value calculated in a five days period before the day preceeding the SSC. The zero level means the mean count rate. Finally, the hourly deviations were normalized by the error of each directional channel to compensate the uneven fluctuation due to different errors (Table 1). From this point on data processed in the following way will be called just as "normalized muon deviation".

Following a previous work [16], we analyze the time-derivative of muon deviations (not normalized) by calculating the difference between the deviation at a time $t$ and the previous one at $\mathrm{t}-1$ with the time $\mathrm{t}$ in hour. After that, the time-derivative of the muon deviations were normalized in a similar way than described in the previous paragraph. For each directional channel in the GMDN, we calculate the pitch angle every hour using the in situ interplanetary magnetic field data at L1 provided by the Advanced Composition Explorer (ACE) spacecraft. Following the time of precursor appearance before the SSC reported by previous studies [6], we plot the pitch angle distribution in a up to seven day period preceding the SSC. For an arbitrary chosen range of 10 degrees of pitch angle for each hour, we calculated the mean of all the directional channels covering that range. As there is a different number of directional channels in each range, the error is normalized by dividing by the square root of the number of directional channels. The bigger the number of directional channels in a given angle range, the smaller the error. After this normalization all the ranges have the same statistical error. As two hourly count rates are used to calculate the time-derivative, the error is increased by square root of two and, for this reason, the results are normalized again. We call this methodology as "VAR" pitch angle. From this point on this will be referred as VPA.

We also calculate the pitch angle distribution of the normalized muon deviation, instead of the time-derivative. We call this methodology as "MUONS" pitch angle, refereed shortly as MPA.

The VPA and MPA pseudo-color plots have a color bar intended to discriminate error from increases or decreases out of the error range. Since the data is normalized by the error, the range from $-1 \%$ to $1 \%$ covers the errors from all directional channels. An arbitrary chosen range with magnitude up to 3\% (30\%) is represented in yellow for VPA (MPA). The remaining increases (decreases) with bigger magnitudes are represented in blue (red). The white rectangles are ten-degree pitch angle ranges that i) do not have coverage in a given hour or ii) have gap on muon data in a given station or iii) have gaps on IMF data because and so we were not able to calculate the pitch angle for any channel of the GMDN. A possible precursor is considerer any group of pitch angle blocks with absolute value higher than 3\% (30\%) observed up to 24 hour before the SSC for VPA (MPA).

For observing transient in the interplanetary medium associated with the SSC, we use interplanetary magnetic field and proton data provided observed at Lagrangean point L1 by Solar Wind Electron, Proton and Alpha Monitor (SWEPAM) onboard the spacecraft Advanced Composition Explorer (ACE). SWEPAM measures particle with energies from about 0.26 up to about $36 \mathrm{keV}$. The sensor is an electrostatic analyzer with fan-shaped field-of-view. The electrostatic analyzers measure the energy per charge of each particle by bending their flight paths through the system. The field-of-view are swept across all solar wind directions by the rotation of the spacecraft [17]. 


\section{Results}

In the period from June $26^{\text {th }} 2008$ to December $31^{\text {th }} 2008$, we found 7 events, see Table 3. The first column of Table 3 is the event number, the second is the date, the third is the time of the SSC (according to Kp index data), the forth is the maximum Kp index recorded for each event, the fifth show the presence or not of a possible precursor (for both MPA and VPA methodologies) and the last column indicate which transient is observed in association with the SSC.

For an arbitrary chosen period not associated to any transient in the interplanetary magnetic filed, we would not expect any decrease/increase bigger than the criterion for the precursor. Otherwise, some decreases/increases were observed prior to the SSC in all events, except for event number 3. These decreases/increases do not follow the precursor criterion described in the previous session because they are present more than $24 \mathrm{~h}$ before the SSC.

The muon data and interplanetary magnetic field and plasma data during the geomagnetic storm on July $12^{\text {th }} 2008$ (event \#1) are shown in Figure 3. The panels of the figure show, from top to bottom, the MPA and VPA pseudo-color map, the magnitude of the interplanetary magnetic field (nT), the ' $\mathrm{z}$ ' component of the interplanetary magnetic filed (nT) in GSM coordinates, the proton temperature $(\mathrm{MK})$, the proton speed $(\mathrm{km} / \mathrm{s})$, the proton density $(\mathrm{cm}-3)$ and the Dst index (nT). The pre-SSC increase of the proton density before the magnetic field suggest a co-rotating interaction region (CIR). There is a interface between a slow and fast solar speed region and a turbulent region in the interface between the regions. The interface region is characterized by an strong decrease in the plasma density, decrease of the proton temperature and of the solar wind speed. Since the Dst index peak is between $-50 \mathrm{nT}$ and $-30 \mathrm{nT}$, the geomagnetic storm is classified as small [18]. Both MPA and VPA satisfy the criterion for classification of precursors of geomagnetic storms. As VPA is the approximate derivative of the deviations, negative values mean a inflection in the deviation curve. This could be due to cosmic ray particles deflected in their patch in the interplanetary medium due to a positive gradient of magnetic field related to an interplanetary transient which was observed after the SSC with a maximum of more than $10 \mathrm{nT}$. As cosmic ray particles have almost the speed of light and the CIR has speed of hundreds of $\mathrm{km} / \mathrm{s}$, cosmic ray particles are observed at the earth surface prior to the transient arrival observation at the Lagrangian point L1, where satellite ACE is located. MPA shows also a signature between days 8 and 9, before the SSC, and between days 14 and 16, after the SSC. 


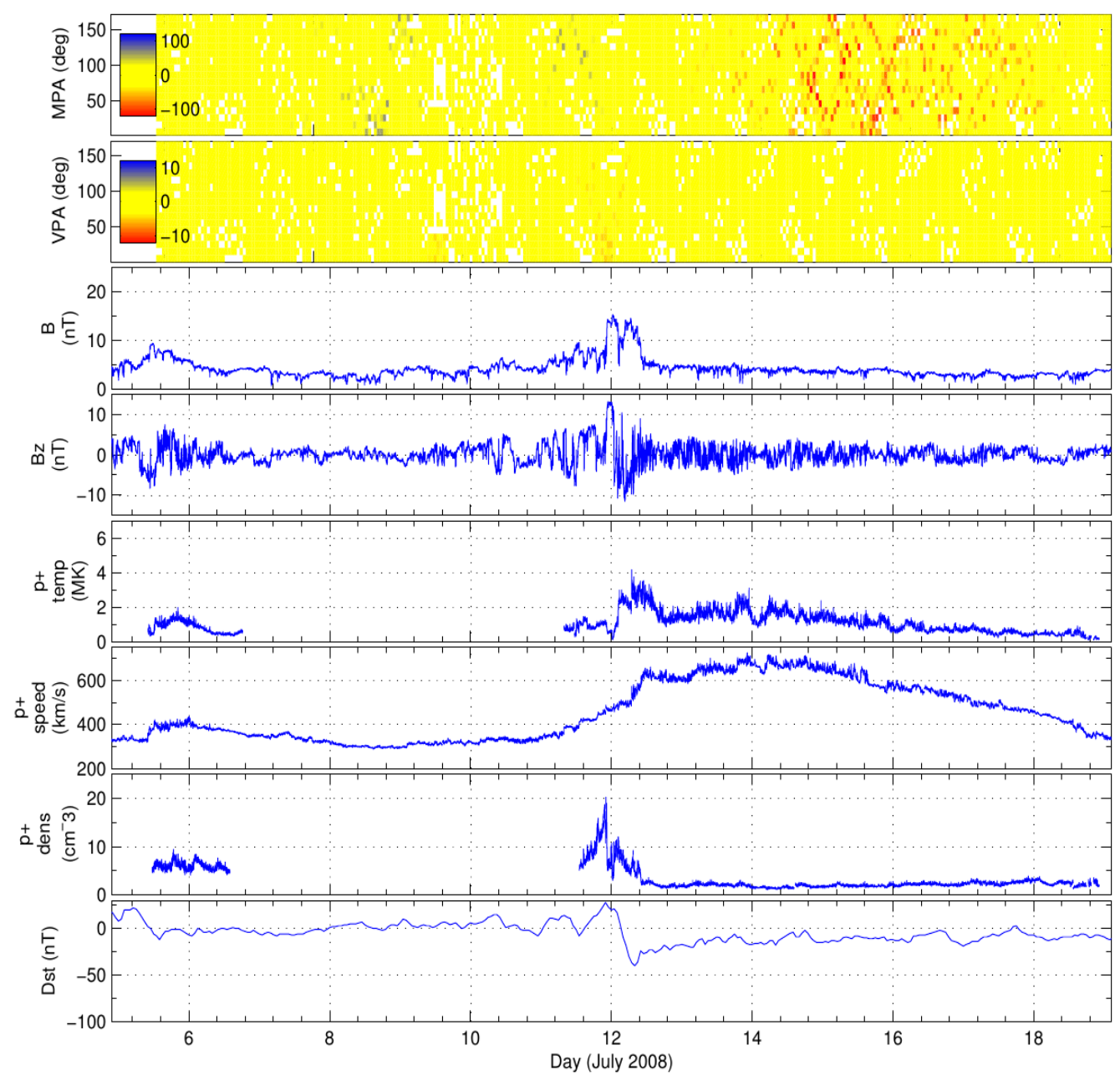

Figure 3: Event \#1: July $12^{\text {th }} 2008$. Co-rotating interaction region associated with a small geomagnetic storm.

Except for event number 7, all the remaining events from Table 3 are associated with CIR.

The muon and interplanetary magnetic field and plasma during the geomagnetic storm on November $24^{\text {th }} 2008$ (event number 7) are shown in Figure 4 (the order of the panels is the same than in Figure 3). Another possible precursor is present. The Dst index does not show any geomagnetic storm, it does show only positive values. Anyway a clear transient is observed in the interplanetary medium: the magnetic field has a sudden increase in magnitude with values higher than 20nT. The proton speed also has a sudden increase. An interplanetary shock associated with ejecta where the ejecta was not directed to the Earth and, as the shock has greater longitudinal extent than the ejecta [19], the shock is detected and the ejecta is not . More than 24 hours in advance to the shock detection a possible precursor can be seen in MPA. After the shock MPA show systematic decreases that are Forbush decreases. 


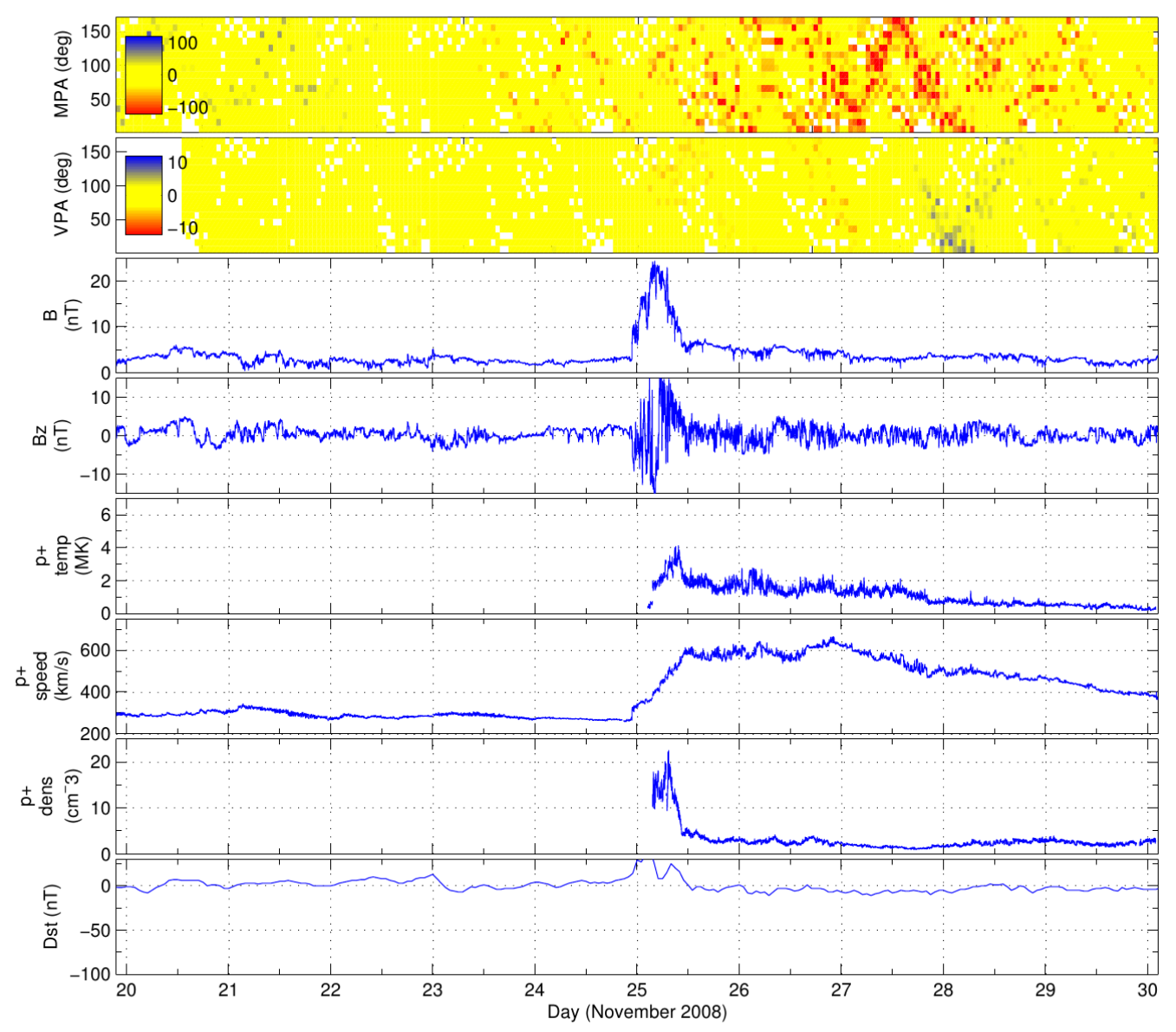

Figure 4: Event \#7: November $24^{\text {th }} 2008$. A co-rotating interacting region associated to a positive Dst index period.

Table 3: Summary of the events analyzed.

\begin{tabular}{|c|c|c|c|c|c|}
\hline$\#$ & Date & Time & Kp peak & Precursor & Transient \\
\hline 1 & $2008 / 07 / 12$ & $00: 38$ & $4+$ & MPA, MPA & CIR \\
\hline 2 & $2008 / 08 / 08$ & $23: 44$ & $5+$ & MPA & CIR \\
\hline 3 & $2008 / 09 / 03$ & $06: 40$ & 6 & none & CIR \\
& & $15: 42$ & & & \\
\hline 4 & $2008 / 09 / 14$ & $19: 13$ & $4-$ & Data not clear & CIR \\
\hline 5 & $2008 / 11 / 07$ & $03: 53$ & $4+$ & MPA, VPA & CIR \\
\hline 6 & $2008 / 11 / 15$ & $16: 25$ & $4-$ & Data not clear & CIR \\
\hline 7 & $2008 / 11 / 24$ & $23: 51$ & $4-$ & MPA & SHOCK \\
\hline
\end{tabular}




\section{Summary}

The correction of the temperature effect on secondary cosmic ray procuction by the 100 $\mathrm{hPa}$ altitude (where this particle are mainly produced) can clearly remove the yearly variation of the count rate regarded to the temperature. The maximum difference between the corrected and not corrected data is about 2\% for all the stations, except for São Martinho da Serra where is about $1 \%$. Unfortunately there are only two measurements in a day and in this way it is very difficult the have accurate correction of the hourly muon count rates in a daily perspective.

More than $50 \%$ of the events analyzed in this article (4 among 7) show some possible precusors, that is, some sistematic increases or decreases in the daily period before the SSC with intensity higher than 3\% (30\%) for VPA (MPA). Unfortunately false precursors are present in the analysis. The MPA methodology shows precursors more frequently than the VPA methodology. Possible precursors can be associated both to CIR and shocks.

More intense geomagnetic activity and/or transient with higher magnetic field are expected to be detected by the GMDN during the next solar maximum. According to the results found by [13], the more intense the geomagnetic storms, the higher the chance of visualization of precursors. Higher percentages of precursors are expected for intese geomagnetic storms (Dst $<-100 \mathrm{nT})$.

\section{Acknowledgements}

We thank to the Fundação de Amparo à Pesquisa do Estado de São Paulo (FAPESP), for funding part of this work under project 2008-08840-0; to Conselho Nacional de Desenvolvimento Científico e Tecnologico - CNPq, for supporting this work under project 303798/2008-4; to the National Science Foundation (NFS) of the USA for a subcontract between Delaware University and FATEC/UFSM from Brazil, for supporting part of the upgrade of the telescope installed in São Martinho da Serra, Brazil. Dst index data were provided by the World Data Center for Geomagnetism, IMF and plasma data by the ACE mission and $\mathrm{Kp}$ and SSC data by the Helmholtz Centre Potsdam German Research Centre for Geosciences. Temperature and altitude radio-data was provided by Natural Environment Research Council (NERC).

We thank to ICTP, CLAF, UST, FAPESP and UFABC for supporting the $4^{\text {th }}$ Cosmic Ray School on Cosmic Ray and Astrophysics.

\section{References}

[1] Gosling, J. T.; Bane, S. J.; McComas, D. J.; Phillips, J. L., Coronal Mass ejections and large geomagnetic storms, Geophysic. Res. Lett., 17, 901-904, 1990.

[2] Kuwabara, T.; Bieber, J. W.; Clem, J.; Evenson, P.; Ryle, R.; Munakata, K. et al. Real-time cosmic ray monitoring system for space weather, Space Weather, 4, S08001, 2006.

[3] Ruffolo, D.; Bieber, J.; Evenson, P.; Pyle, R. Precursors to Forbush decrease and space weather prediction, Proc. Int. Cosmic Ray Conf. 26th., xvi, 53, 1999.

[4] Dorman, L. I., Geophysical and Astrophysical Aspects of Cosmic Rays, Prog. Phys, Cosmic Ray Elementary Particles, ser. vol. 7, 320pp., North-Holland, New York, 1963. 
[5] Nagashima, K.; Fujimoto, K.; Sakakibara, S. et al. Local-time-dependent pre-IMF-shock decrease and post-shock increase of cosmic rays, produced relatively by their IMF-collimated outward and inward flows across the shock responsible for Forbush decrease, Planet. Space Sci., 40, 1109-1137, 1992.

[6] Munakata, K.; Bieber, J. W.; Yasue, S.; Kato, C.; Koyama, M.; Akahane, S. et al. Precursors of geomagnetic storms observed by muon detectors, J. Geophys. Res., 105, A12, 27427-27468, 2000 .

[7] Belov, A. V.; Bieber, J. W.; Eroshenko, E. A.; Evenson, P.; Pyle, R.; Yanke, V. G., Pitch angle features in cosmic rays in advance of severe magnetic storms: neutron monitor observations, Proceedings of the 27th ICRC, Hamburg, 3507-3510, 2001.

[8] Kudela, K., Storini, M., Possible tools for space weather issues from cosmic ray continuous records, Adv. Space Res., 37 (8), 1443-1449, 2006.

[9] Leerungnavarat, K.; Ruffolo, D.; Bieber, J. W., Loss cone precursors to Forbush decreases and advance warning of space weather effects, Astrophys. J., 593 (1), 587-596, 2003.

[10] Okazaki, Y., Fushishita, A., Narumi, T., Kato, C., Yasue, S., Kuwabara, T., Bieber, J. W. et al., Drift effects and the cosmic ray density gradient in a solar rotation period: first observation with the global muon detector network (GMDN), Astrophys J., 681, 2008.

[11] Murakami, K.; Nagashima, K.; Sagisaka, S.; Mishima, Y.; Inoue, A., Response function for cosmic-ray muons at various depths underground, Nuovo Cimento C, v. 2C, 635-651, 1979

[12] Lin, Z.; Bieber, J. W.; Evenson, P. 1995, J. Geophys. Res., 100, 23543.

[13] Da Silva, M. R. Detecção de distúrbios solar-interplanetários combinando observações de satélite e de raios cósmicos de superfície para aplicação em clima espacial. 2009. 140 p. (INPE-16649-TDI/1612). PhD. Dissertation - Instituto Nacional de Pesquisas Espaciais, São José dos Campos, Brazil. 2010. Available on: <http://urlib.net/sid.inpe.br/mtcm19@80/2009/11.30.12.58>. Access: 05 nov. 2010.

[14] Blackett, P. H. On the instability of the barytron and the temperature effect of comic ray, Phys. Rev., 54 973-974, 1938.

[15] Sagisaka, S. (1986), Atmospheric effects on cosmic-ray muon intensities at deep underground depths, Il Nuovo Cim., 9C, 809-828.

[16] Braga, C. R; Schuch, N. J.; Da Silva, S. M.; Kemmerich, N.; Silveira, M. V. D.; Kummer, F. D. et al., Technical aspects and analysis of the cosmic ray modulation effects during geomagnetic storms, 37th Cospar Scientific Assembly, 2008d.

[17] McComas, D. J.; Bame, S. J.;Barker, P.; Feldman, W. C.;Phillips, J. L.; Riley, P.;Griffee, J. W. Solar Wind Electron Proton Alpha Monitor (SWEPAM) for the Advanced Composition Explorer, Spc. Sci. Rev., 86, 563-612, 1998

[18] Gonzalez, W. D.; Joselyn, J. A.; Kamide, Y.; Kroehl, H. W.; Rostoker, G.; Tsurutani, B. T.; Vasyliunas, V. M., What is a magnetic storm? , J. Geophys. Res., v.99, n.A4, 5771-5792, 1994.

[19] Cane, H. V. Coronal Mass Ejections and Forbush Decreases, Spa. Sci. Rev, 93: 55-57, 2000 